\title{
The Optimal Strategies of Risk-Averse Newsvendor Model for a Dyadic Supply Chain with Financing Service
}

\author{
Jianxin Chen \\ School of Applied Mathematics, Guangdong University of Technology, Guangzhou 510520, China \\ Correspondence should be addressed to Jianxin Chen; chenjianxin403@163.com
}

Received 26 October 2016; Revised 27 January 2017; Accepted 6 February 2017; Published 28 February 2017

Academic Editor: Gabriella Bretti

Copyright (c) 2017 Jianxin Chen. This is an open access article distributed under the Creative Commons Attribution License, which permits unrestricted use, distribution, and reproduction in any medium, provided the original work is properly cited.

\begin{abstract}
This paper studies the budget-constrained newsvendor problem under risk aversion with financing service and builds a two-stage supply chain decision model on the order quantity and wholesale price. The budget-constrained retailer as a newsvendor faces a nonnegative random demand and the financial institution provides the loan service for the retailer who is risk-averse. This paper first explores the impact of risk aversion on the decisions in financial supply chain. Different from the existing research, we analyze how the financing service of bank loan impacts the risk-averse newsvendor's decision and how the risk-averse behavior of the retailer influences the optimal strategies in supply chain with CVaR risk measure criterion. It is found that the order quantity decreases in the degree of risk aversion. The optimal order quantity is decreasing in initial budget, wholesale price, and interest rate. It is worth noting that the financing service can improve the profit of the supply chain system when the retailer has a low initial wealth. Finally, to compare with the existing results the theoretical analysis and numerical examples are also illustrated.
\end{abstract}

\section{Introduction}

Recently supply chain management has been more and more perfect in the information flow and logistics. However, the equally important cash flow has not been synchronized with development and the related academic research is also relatively scarce. In traditional newsvendor model it is implicitly assumed that the newsvendor generally pays the supplier for all the ordered items and capital is sufficient. Thus, the financial market is obtained for powerful suppliers or retailers in developed economies. Empirical studies show that budget constraint is usually a great challenge for many firms (especially start-up, small-, and medium-sized ones). Using data for 76 countries, Ayyagari et al. [1] demonstrated that nearly $60 \%$ of manufacturing employment was from start-up, small-, and medium-sized ones. However, startup, small-, and medium-sized enterprises often do not have sufficient working capital to make their optimal decisions for manufacturing and marketing.

Bank loans are a very important financing service provided by financing institutes in the development for budget-constrained small- and medium-sized enterprises. In real applications, many financing institutes are willing to provide the retailer with a loan when the retailer is budget-constrained. For example, Bradley and Rubach (2002) conducted a survey of 3561 representative U.S. small businesses and found that $60 \%$ of them had to resort to the financing service of bank loan. Borrowing money from outside financial institutions is a possible way to resolve the financial constraints and to increase the profit; Bai and Zhang [2] pointed out that it was important to incorporate the firm's financial concerns into its operational decisions.

In developing economics where firms have limited access to credits and financial service, budget constraints may influence more the operational decisions in a supply chain. Even in developed economics, because of globalization competition, there would not be no surprise that a firm has budget constraint on its operation. As a result, budget constraints on such a firm may degrade its performance and the performance of entire supply chain as well. For example, in 2007, one famous state-owned 3PL firm offered financial service to budget-constrained firms and helped firms to raise funds from banks more than 2 billion dollars based on asset ([3]; Birge and Zhang, 2004). Our research is motivated by the practice of the finance in China. 
The purpose of this paper is to take a first step to understanding the impacts of bank financing service when the retailer is risk-averse, the monopolistic or competitive financial market on the decisions, and the performance in a budget-constrained supply chain. We just use a simple supply chain to analyze the decision-making in our setting, which will play important roles of illumination and reference for the real business. However, to the best of our knowledge, the current research on the interface of operation and finance management mainly focuses on the traditional product supply chain. The research of simultaneously considering risk attitude newsvendor model and the bank financing service has drawn little attention. Through the literature search, so far there are only two papers simultaneously considering decision maker's behavior and financing in the supply chain management field. One is the research of $\mathrm{Ma}$ et al. [4]. In a periodic review setting, they studied an inventory control problem in a finite horizon for a loss-averse retailer with financial constraints. They explored how the retailer's loss-averse behavior affected the optimal policies of budget-constrained supply chain. In their setting, the retailer financed his inventory through bank credit financing mode and the retailer could directly borrow from an outside cash provider to finance his inventory decision during the planning horizon. The other paper is the research of Zhang et al. [5]. They investigated the impacts of capital constraints and loss aversion on the operational decisions in a supply chain. In their paper, the best pricing and ordering decisions of both manufacturer and retailer were determined, and results demonstrated how these key decisions were influenced by their initial capital, loss-aversion coefficient, and the bank's financial decisions. Different from the above two papers, however, in the paper we address this issue by considering the retailer's risk aversion and bank financing service. Our model is mainly based on the research of Chen [6] and Chen and Cai [7]. And the model setup is also the same as theirs. But in their papers, the retailer is risk-neutral. In practice people are not only concerned about their own profits, but also concerned about the risk. The assumption of risk neutrality seems to be improper in supply chain management. So we adopt CVaR, the risk measure commonly used in finance, as the decision criterion, and explore how the optimal strategies of newsvendor and supplier depend on the decision maker's risk aversion and initial budget.

Recently, risk attitude has been an important issue in the areas of supply chain management, although the extant literatures typically assume that the retailer is risk-neutral, as evidenced in reality. There is decision bias when decision maker chooses the order quantity decisions by maximizing the expected profit or minimizing the expected cost. Because of the complexity of the economic environment, the uncertainty of market demand and information asymmetry and so forth, in the face of the market retailer, will take different risk attitudes. Decision makers do have risk preference other than risk neutrality. That many decision makers are risk-averse has been amply documented in the finance and economics literature; see, for example, Neumann and Morgenstern [8], Markowitz (1959), Jorion [9], and Szegö [10]. In supply chain management, risk-averse is major preference that has been extensively studied in literature (see [11-14]). It is well known that there are three major risk formulations that are widely used in finance literature: mean-variance and its variants, Value-at-Risk, and Conditional Value-at-Risk (for detailed discussion, see, e.g., [15] and references therein). All of them have been widely applied although each of them has certain strengths as well as limitations [16]. Unlike VaR, CVaR takes into account both reward and risk and is shown to be a coherent risk measure and has better computational characteristics. CVaR, as a new development measure of risk, has drawn a great deal of attention (see [17, 18]). Recently, CVaR has also been adopted in operation management such as Chen et al. (2003) [15], Tomlin and Wang [19], and Gotoh and Takano [20].

In summary, in this paper, we consider a dyadic supply chain, in which the supplier is the leader and the retailer is the follower as a Stackelberg game. The risk-averse retailer sells a product with stochastic demand and places an order quantity from a risk-neutral supplier who decides on the wholesale price. We investigate the impacts of the degree of risk aversion on the optimal ordering decisions with bank financing loan service in risk-averse setting where the channel consists of a risk-neutral supplier and a risk-averse retailer, and the retailer takes CVaR as his performance measure. Our model is different from the existing literature and we focus on the following aspects. (1) In our paper we introduce both the budget constraints and the risk aversion of newsvendor into supply chain management. (2) We analyze how retailer's risk aversion may influence the operational and financial decisions of the budget-constrained firm. (3) We investigate how both bank financing service and retailer's risk attitude may influence the value of individual firm and the entire supply chain.

The rest of this paper is organized as follows. In Section 2, we review the related literature. In Section 3, we give the model descriptions and notations used in the paper and some preliminaries. Section 4 studies the strategies of the riskaverse retailer and risk-neutral supplier. Section 5 illustrates some numerical examples. At last, the conclusions are given.

\section{Literature Review}

Our work belongs to the interface of financial and behavioral operations, which is related to two streams of research. The first stream focuses on the effect of risk aversion, mainly by studying how risk aversion influences the decision-making of the agents in supply chain and the performance of the supply chain. The research about risk aversion is mainly based on CVaR criterion, which has been widely applied in the newsvendor problem recently. There are a number of studies addressing the risk aversion issue through use of $\mathrm{CVaR}$ in the area of operation management. For example, under the CVaR measure, Chen and Sim et al. (2003) proposed a model about CVaR of profit for newsvendor problem and obtained the optimal order quantity, Gotoh and Takano [20] studied linear programming formulation for minimizing CVaR in the newsvendor problem, Choi and Ruszczyński [21] derived an equivalent representation of a risk-averse newsvendor problem as a mean-risk model for general law invariant 
coherent measures of risk, Chen et al. [15] addressed the combined price and order quantity decisions of a risk-averse newsvendor, Ma et al. [22] considered a supply chain with a risk-neutral manufacturer and a risk-averse retailer, $\mathrm{Xu}$ and Meng et al. (2013) introduced a trilevel model for the threestage supply chain, and Katariya and Cetinkaya et al. (2013) investigated the relationship between risk-neutral and riskaverse newsvendor problems. Those models do not include the pricing decision. Wu et al. [23] studied a risk-averse newsvendor problem with quantity competition and price competition. Under the Conditional Value-at-Risk (CVaR) criterion, they characterized the optimal quantity and pricing decisions under both quantity and price competition. Dai and Meng [24] analyzed a single-period inventory model where a risk-averse newsvendor made a joint decision on ordering, pricing, and marketing under the CVaR risk measure criterion. All above work assume that the supply chain system is well funded.

The second stream of related research is budgetconstrained literature. During the past two or three decades, traditional supply chain management models mostly ignored the issues of financing. The reason is in that Modigliani and Miller [25] proved that a firm's financing and operational decisions could be made separately in a perfect capital market. However, after Harris and Raviv [26] pointed out that the capital market was not perfect in reality, many researchers realized the importance of the interaction between operational and financing decisions and started to incorporate the issue of supply chain financing into the traditional supply chain management models. For example, Babich and Sobel [27] and Buzacott and Zhang [28] researched the strategy of the enterprise under budget constraints and their results were published in the journal of Management Science in 2004, which showed that the research fields were beginning to receive attention. Trade credit financing (TCF) is the most important form of short-term supply chain financing, which is widely used in both developed countries like United States [29] and developing countries like China [30]. Most of the existing related literature considering financing focused on TCF mode. They mostly analyzed how TCF influenced the retailer's optimal order decision and/or supply chain coordination under the classical EOQ/EPQ framework (such as [31-37]) or under the newsvendor framework (such as [3840]). Bank credit financing (BCF) is one of the supply chain external financing modes. There are also a few of researchers who discussed supply chain members' pricing/ordering decisions under BCF mode. For example, Zhou and Groenevelt [41] considered a three-party supply chain consisting of a core manufacturer, a capital-constrained retailer, and a bank. They showed that BCF was preferable to both the retailer and the overall supply chain but not preferable to the manufacturer. Kouvelis and Zhao (2012) considered a supply chain consisting of a supplier and a capital-constrained retailer. Different from Zhou and Groenevelt [41], they assumed that the retailer needed to repay the loan interest by himself. Consequently, they showed that the retailer would always prefer TCF mode to BCF mode. Similar to Kouvelis and Zhao (2012), Jing, Chen, and Cai (2012) considered a distribution channel that consisted of a manufacturer with deep pocket and a capital-constrained retailer. In their paper, the retailer might fund its business through TCF and/or BCF mode if needed. Moreover, the manufacturer offered full trade credit under the TCF mode, which was different from Kouvelis and Zhao (2012). They showed that if only TCF or BCF were viable, TCF became less attractive than BCF for the retailer; if both TCF and $\mathrm{BCF}$ were viable, the retailer preferred TCF if production cost was relatively low but preferred BCF otherwise. Recently, Chen (2015) also considered a dyadic supply chain model with TCF or BCF mode. He mainly compared the effects of TCF and BCF modes on the channel efficiency improved by wholesale price and revenue sharing contracts, respectively. Yan, Sun, and Zhang (2016) further focused on partially credit-guaranteed bank financing (PCGBF), an innovative SCF scheme initiated in 2013 [42] by a Chinese commercial bank, Evergrowing Bank, under which the core member in the supply chain needed to offer partial credit guarantee for its up/downstream capital-constrained partners so that they could obtain loans from the bank. They explored the impact of the credit guarantee coefficient on the supply chain members' optimal strategies and revealed that the PCGBF scheme might realize channel coordination under certain conditions. In addition, scholars like Dada and $\mathrm{Hu}$ [43], Lee and Rhee [44], Kouvelis and Zhao [45], Feng et al. [46], and so forth also made similar researches. However, all the above works assume that supply chain members are all risk-neutral and focus on discussion of the operational decisions and financial decisions. None of these studies consider the riskaverse behavior of the decision maker. To cover the research gap in this stream, this paper will discuss the combined impact of risk aversion and bank financing service on the supply chain members' decisions, which is different from the existing literature.

This paper's scenario involves a risk-averse retailer facing a stochastic demand. Generally speaking, supply chain members are all probably risk-averse in reality. Why is the supplier not risk-averse? The reasons that we make this assumption are three aspects below. One is that, in this paper, the focus is on just the demand uncertainty, not other risks including manufacturing risk, delivery risk, and so forth. The unknown market demand within the supply chain creates uncertainty for the retailer in that his revenue might be lower than his cost (product cost and financing cost). The retailer bears the uncertainty. So the supplier is risk-neutral in our model. The other is because the core supplier acts as the leader, whereas the retailer is a follower in the supply chain. As in Gan et al. [47], the risk-neutrality assumption on part of the supplier was reasonable when it was able to diversify its risk by serving a number of independent retailers, which was quite often the case in practice. When the retailers are independent decision makers, the supply chain can be divided into a number of subchains, each consisting of one supplier and one retailer. In this case, it is enough to study a supply chain consisting of one risk-neutral supplier and one risk-averse retailer. The last one is that this assumption is also used by other researchers. For example, Yang et al. [16] investigated supply chain coordination with a risk-neutral supplier and a risk-averse retailer where the retailer optimized his CVaR performance measure under some commonly used four 
supply contracts (including revenue sharing, buy-back, twopart tariff, and quantity-flexibility contracts). In a supply chain consisting of one risk-neutral manufacturer and two risk-averse retailers under a single-period setting with pricesensitive random demand, Hsieh and $\mathrm{Lu}$ [48] studied the manufacturer's return policy and the retailer's decisions. Xiao and Yang (2008) analyzed the effects of the retailer's risk sensitivity on the player's optimal strategies with one risk-neutral supplier and one risk-averse retailer. Ma et al. [22] modelled the problem as a Nash-bargaining problem where the manufacturer and the retailer negotiated about the wholesale price and order quantity. In their setting, the retailer was risk-averse with CVaR and the manufacturer was risk-neutral. Xu et al. [49] extended the revenue sharing contract and two-part tariff contract in a two-echelon fashion supply chain when the demand was sensitive to retail price. Li et al. [50] investigated a dual-channel supply chain with one risk-neutral manufacturer and one risk-averse retailer where there was only one perishable product with pricedependent stochastic demand. Li et al. [51] considered a dualchannel supply chain consisting of a risk-neutral supplier and a risk-averse retailer, in which the market demand was uncertain and the supplier opened an e-channel, thus directly participating in the market.

Our research makes contributions to the literature in three aspects. First, we simultaneously incorporate supply chain financing and the risk-averse behavior of the decision maker into traditional supply chain models. Our aim is to study their combined effect on supply chain members' equilibrium pricing/ordering strategies. Moreover, our research considers the bank loan financing service, the external financing mode used in practice. Second, we adopt CVaR, the risk measure commonly, as the decision criterion, to measure the retailer's risk preference in a dyadic supply chain, which is the approach in finance fields. Then, a risk-averse model is established to determine the optimal pricing/ordering strategies of the dyadic supply chain with a budget-constrained retailer under bank financing service mode. Lastly, we investigate the impacts of the degree of the retailer's risk aversion and the retailer's initial capital on supply chain members' optimal pricing/ordering strategies.

\section{Model Descriptions and Preliminaries}

3.1. Model Descriptions and Preliminaries about CVaR. We consider a simple supply chain consisted of a core supplier and an averse-risk retailer with budget constraints. The supplier is neutral and well financed. The financial institution (the bank) provides the loan for the risk-averse retailer with interest rate $r$ and the retailer faces a nonnegative stochastic demand $\xi$ with a distribution function (similar models are discussed in $[52,53]$ ). At the beginning of a selling season, the supplier as the leader needs to make decision of optimal wholesale price and a decision on order quantity of newsvendor is made for the season. Additionally, the budgetconstrained newsvendor needs to borrow from bank with interest rate $r$. We assume that the products have no salvage. The notations are summarized as follows. $\xi$ : the market demand being nonnegative stochastic with the probability density function $f(x)$ and the cumulative distribution function $F(x)$, respectively. Let $\bar{F}(x)=1-F(x)$ and $h(x)=f(x) / \bar{F}(x)$ be the failure rate and $H(x)=x f(x) / \bar{F}(x)$ be the generalized failure rate, which are assumed to be increasing.

Q: the order quantity of the retailer.

$B$ : the retailer's initial budget.

$p$ : the unit retail price. Without loss of generality assumption, we set $p=1$.

$w$ : the wholesale price.

$c$ : the unit production cost.

$r$ : newsvendor's financing interest rate of loan.

To avoid trivial cases, we assume that $1=p>w(1+r)>$ $c(1+r)>c$. Notice that if $w(1+r)>p$, the retailer does not order, and if $w<c$, the supplier is not profitable.

We adopt the CVaR criterion to model risk aversion. To begin with, we briefly describe the CVaR performance measure. Rockafellar and Uryasev $[17,18]$ introduced the famous risk measure CVaR. It has some attractive properties which make it widely used in risk management. CVaR about $l(x, \xi)$ under the confidence level $\eta$ can be defined as

$$
\begin{gathered}
\operatorname{CVaR}_{\eta}[l(x, \xi)]=E\left[l(x, \xi) \mid l(x, \xi) \geq \operatorname{VaR}_{\eta}(l(x, \xi))\right] \\
=\frac{1}{1-\eta} \int_{l(x, \xi) \geq \operatorname{VaR}_{\eta}(l(x, \xi))} l(x, \xi) \phi(z) d z,
\end{gathered}
$$

where $\phi(z)$ is the probability density function of the random variable $\xi$ and $\operatorname{VaR}_{\eta}(l(x, \xi))=\inf \{y \in R \mid \operatorname{Pr}\{l(x, \xi) \leq y\} \geq$ $\eta$ \}. To compute, Rockafellar and Uryasev [17] introduced a function of $F(x, \xi, u)=u+(1 /(1-\eta)) E[l(x, \xi)-u]^{+}$and proved the minimum of $\mathrm{CVaR}_{\eta}[l(x, \xi)]$ could be obtained by minimizing the function $F(x, \xi, u)$. For the convenience of calculation, the equivalent form of CVaR is employed as follows.

$$
\begin{aligned}
& \operatorname{CVaR}_{\eta}[g(x, y)] \\
& \quad=\max _{v \in R}\left\{v+\frac{1}{\eta} E[\min (g(x, y), 0)]\right\} .
\end{aligned}
$$

\subsection{Conclusions Concerned with the Study in This Paper}

3.2.1. The Centralized Case. When decision makers are riskneutral, the expected profit of the whole supply chain $E\left[\pi^{C}(Q)\right]$ in traditional supply chain can be rewritten as follows.

$$
E\left[\pi^{C}(Q)\right]=E[\min \{x, Q\}-c Q]
$$

The optimal centralized order quantity $Q^{C}$ is

$$
Q^{C}=\bar{F}^{-1}(c) \text {. }
$$


3.2.2. The Decentralized Case. When the retailer has sufficient capital to order from the supplier, the expected profit of retailer $E\left[\pi_{r}^{N}(Q)\right]$ can be rewritten as $E\left[\pi_{r}^{N}(Q)\right]=$ $E[\min \{x, Q\}-w Q]$.

The optimal order quantity of risk-averse retailer is

$$
(1-w)=\frac{1}{\eta} F\left(Q^{N}\right) .
$$

When the retailer is budget-constrained and has no finance services, the optimal order quantity is

$$
Q_{0}=\min \left\{\frac{B}{w}, Q^{N}\right\}
$$

\section{Main Results}

The section details the strategies of the risk-averse retailer and risk-neutral supplier.

4.1. The Risk-Averse Newsvendor Model with Financing Service. Retailer's expected profit is

$$
\begin{aligned}
E[ & \left.\pi_{r}^{N}(Q)\right] \\
= & \int_{0}^{+\infty}[\min \{x, Q\}-(w Q-B)(1+r)]^{+} f(x) d x \\
& \quad-B .
\end{aligned}
$$

$$
v^{*}=\left\{\begin{array}{l}
-B, \\
F^{-1}(\eta)-(w Q-B)(1+r)-B, \\
Q-(w Q-B)(1+r)-B,
\end{array}\right.
$$

Proof. (1) If $-B>v$, we have $k(Q, v)=v, \partial k(Q, v) / \partial v=1$.

(2) If $-B \leq v \leq Q-(w Q-B)(1+r)-B$, we have

$$
\begin{aligned}
& k(Q, v)=v-\frac{1}{\eta} \int_{0}^{(w Q-B)(1+r)}(v+B) f(x) d x-\frac{1}{\eta} \\
& \cdot \int_{(w Q-B)(1+r)}^{v+(w Q-B)(1+r)+B} v f(x) d x-\frac{1}{\eta} \\
& \cdot \int_{(w Q-B)(1+r)}^{v+(w Q-B)(1+r)+B}[-x+(w Q-B)(1+r)+B] \\
& \cdot f(x) d x,\left.\quad \frac{\partial k(Q, v)}{\partial v}\right|_{v=-B}=1-\frac{1}{\eta} F[(w Q-B)(1+r)], \\
& \left.\frac{\partial k(Q, v)}{\partial v}\right|_{v=Q-(w Q-B)(1+r)-B}=1-\frac{1}{\eta} F(Q) .
\end{aligned}
$$

Maximizing the retailer's expected profit we can obtain the optimal order quantity is

$$
\bar{F}\left(\bar{Q}^{*}\right)=w(1+r) \bar{F}\left[\left(w \bar{Q}^{*}-B\right)(1+r)\right] .
$$

Under the CVaR criterion, the problem confronted by risk-averse newsvendor is to find out the optimal ordering to maximize his CVaR; that is,

$$
\begin{aligned}
\max _{Q \geq 0} & \mathrm{CVaR}_{\eta}\left[\pi_{r}(\mathrm{Q})\right] \\
& =\max _{\mathrm{Q} \geq 0} \max _{v^{*} \in R}\left\{k(\mathrm{Q}, v)=v-\frac{1}{\eta} E\left[v-\pi_{r}(\mathrm{Q})\right]^{+}\right\} .
\end{aligned}
$$

From (7) we can state $k(Q, v)$ as

$$
\begin{gathered}
k(Q, v)=v-\frac{1}{\eta} \int_{0}^{(w Q-B)(1+r)}[v+B]^{+} f(x) d x-\frac{1}{\eta} \\
\cdot \int_{(w Q-B)(1+r)}^{Q}[v-x+(w Q-B)(1+r)+B]^{+} \\
\cdot f(x) d x-\frac{1}{\eta} \\
\cdot \int_{Q}^{+\infty}[v-Q+(w Q-B)(1+r)+B]^{+} f(x) d x .
\end{gathered}
$$

We divide the domain of $v$ into three intervals to discuss them and Theorem 1 is obtained.

Theorem 1. Under the criterion of $\eta-C V a R$, for given riskaverse factor $\eta$, the optimal $v^{*}$ satisfying $C V a R_{\eta}\left[\pi_{r}(Q)\right]=$ $\max _{v^{*} \in R}\{k(Q, v)\}$ is

$$
\begin{aligned}
& 0<\eta<F[(w Q-B)(1+r)] \\
& F[(w Q-B)(1+r)]<\eta<F(Q) \\
& \eta>F(Q)
\end{aligned}
$$

(3) If $v \geq Q-(w Q-B)(1+r)-B$, we have

$$
\begin{aligned}
& k(Q, v)=v-\frac{1}{\eta} \int_{0}^{(w Q-B)(1+r)}(v+B) f(x) d x-\frac{1}{\eta} \\
& \cdot \int_{(w Q-B)(1+r)}^{Q}[v-x+(w Q-B)(1+r)+B] \\
& \cdot f(x) d x-\frac{1}{\eta} \\
& \cdot \int_{Q}^{+\infty}[v-Q+(w Q-B)(1+r)+B] f(x) d x
\end{aligned}
$$

and $\partial k(Q, v) / \partial v=1-1 / \eta<0$. Therefore, Theorem 1 is obtained.

According to Theorem 1 , it concludes that $k(\mathrm{Q}, v)$ is continuously differentiable in $v$ except at the point $v=$ 
$Q-(w Q-B)(1+r)-B$. The following theorem gives the retailer's optimal order quantity under $\eta$-CVaR criterion for bank financing service.

Theorem 2. In the decentralized case, under the criterion of $\eta-C V a R$, the optimal order quantity $Q^{*}$ of the budgetconstrained and risk-averse retailer is

$$
\begin{aligned}
& \left(1-\frac{1}{\eta}\right)[1-w(1+r)]+\frac{1}{\eta} \bar{F}\left(Q^{*}\right) \\
& \quad=\frac{1}{\eta}[w(1+r)] \bar{F}\left[\left(w Q^{*}-B\right)(1+r)\right] .
\end{aligned}
$$

Proof. (1) If $v^{*}=-B$, we have $k\left(Q, v^{*}\right)=-B$.

(2) If $v^{*}=F^{-1}(\eta)-(w Q-B)(1+r)-B$, we have

$$
\begin{aligned}
k\left(Q, v^{*}\right) & \\
= & F^{-1}(\eta)-(w Q-B)(1+r)-B \\
& -\frac{1}{\eta} \int_{0}^{(w Q-B)(1+r)} F^{-1}(\eta) f(x) d x \\
& +\frac{1}{\eta} \int_{0}^{(w Q-B)(1+r)}(w Q-B)(1+r) f(x) d x \\
& -\frac{1}{\eta} \int_{(w Q-B)(1+r)}^{F^{-1}(\eta)}\left[F^{-1}(\eta)-x\right] f(x) d x,
\end{aligned}
$$

$$
\begin{aligned}
& \frac{\partial k\left(Q, v^{*}\right)}{\partial Q} \\
& \quad=-w(1+r)+\frac{1}{\eta}[w(1+r)] \int_{0}^{(w Q-B)(1+r)} f(x) d x .
\end{aligned}
$$

Hence,

$$
\begin{aligned}
\frac{\partial^{2} k\left(Q, v^{*}\right)}{\partial Q^{2}} & =\frac{1}{\eta}[w(1+r)]^{2} f[(w Q-B)(1+r)] \\
& >0
\end{aligned}
$$

(3) If $v^{*}=Q-(w Q-B)(1+r)-B$, we have

$$
\begin{aligned}
k\left(Q, v^{*}\right) & \\
= & Q-(w Q-B)(1+r)-B-\frac{1}{\eta} \int_{0}^{Q} Q f(x) d x \\
& +\frac{1}{\eta} \int_{0}^{(w Q-B)(1+r)}(w Q-B)(1+r) f(x) d x \\
& +\frac{1}{\eta} \int_{(w Q-B)(1+r)}^{Q} x f(x) d x,
\end{aligned}
$$

$$
\begin{aligned}
& \frac{\partial k\left(Q, v^{*}\right)}{\partial Q} \\
& =1-w(1+r)-\frac{1}{\eta} \int_{0}^{Q} f(x) d x \\
& \quad+\frac{1}{\eta}[w(1+r)] \int_{0}^{(w Q-B)(1+r)} f(x) d x .
\end{aligned}
$$

We take the first-order derivative of the above equation and obtain

$$
\begin{aligned}
\frac{\partial k\left(Q, v^{*}\right)}{\partial Q}= & \left(1-\frac{1}{\eta}\right)[1-w(1+r)]+\frac{1}{\eta} \bar{F}\left(Q^{*}\right) \\
& -\frac{1}{\eta}[w(1+r)] \bar{F}\left[\left(w Q^{*}-B\right)(1+r)\right] .
\end{aligned}
$$

Notice that

$$
\begin{aligned}
& \left(1-\frac{1}{\eta}\right)[1-w(1+r)]+\frac{1}{\eta} \bar{F}\left(Q^{*}\right) \\
& =\frac{1}{\eta}[w(1+r)] \bar{F}\left[\left(w Q^{*}-B\right)(1+r)\right], \\
& \qquad\left(1-\frac{1}{\eta}\right)<0 .
\end{aligned}
$$

Thus

$$
\begin{gathered}
\frac{\partial^{2} k\left(Q, v^{*}\right)}{\partial Q^{2}}=\left\{\frac{1}{\eta}[w(1+r)] \bar{F}[(w Q-B)(1+r)]\right\} \\
\cdot\left\{\frac{-(1 / \eta) f(Q)}{(1-1 / \eta)[1-w(1+r)]+(1 / \eta) \bar{F}(Q)}\right.
\end{gathered}
$$

$$
\begin{aligned}
& \left.+[w(1+r)] \frac{f[(w Q-B)(1+r)]}{\bar{F}[(w Q-B)(1+r)]}\right\} \\
& <\left\{\frac{1}{\eta}[w(1+r)] \bar{F}[(w Q-B)(1+r)]\right\} \\
& \cdot\left\{\frac{-(1 / \eta) f(Q)}{(1 / \eta) \bar{F}(Q)}\right. \\
& \left.+[w(1+r)] \frac{f[(w Q-B)(1+r)]}{\bar{F}[(w Q-B)(1+r)]}\right\} \\
& =\left\{\frac{1}{\eta}[w(1+r)] \bar{F}[(w Q-B)(1+r)]\right\}\{-h(Q) \\
& +[w(1+r)] h[(w Q-B)(1+r)]\}<0 .
\end{aligned}
$$

From Theorem 2, it is intuitive that under bank financing service the retailer's optimal order quantity is related to the initial capital, financing interest rate of loan, and the 
risk-averse coefficient. That is to say, we can show that, in budget-constrained supply chain, the retailer's operational decisions and financial decisions can not be separated. Notice that the smaller $\eta$ is, the more risk-averse the newsvendor is. Thus, the following corollary is obtained.

Corollary 3. Under the criterion of $\eta-C V a R$, the optimal order quantity of the budget-constrained and risk-averse retailer $Q^{*}$ is increasing in risk-averse factor $\eta$.
Proof. Let

$$
\begin{aligned}
G\left(Q^{*}, \eta\right)= & \left(1-\frac{1}{\eta}\right)[1-w(1+r)]+\frac{1}{\eta} \bar{F}\left(Q^{*}\right) \\
& -\frac{1}{\eta}[w(1+r)] \bar{F}\left[\left(w Q^{*}-B\right)(1+r)\right] .
\end{aligned}
$$

Applying the implicit function theorem, $1-w(1+r)>0$ and $-f\left(Q^{*}\right)+[w(1+r)]^{2} f\left[\left(w Q^{*}-B\right)(1+r)\right]<0$ yields

$$
\begin{aligned}
\frac{\partial Q^{*}}{\partial \eta} & =-\frac{\partial G\left(Q^{*}, \eta\right) / \partial \eta}{\partial G\left(Q^{*}, \eta\right) / \partial Q^{*}}=-\frac{\left(1 / \eta^{2}\right)[1-w(1+r)]-\left(1 / \eta^{2}\right) \bar{F}\left(Q^{*}\right)+\left(1 / \eta^{2}\right) w(1+r) \bar{F}[(w Q-B)(1+r)]}{-(1 / \eta) f\left(Q^{*}\right)+(1 / \eta)[w(1+r)]^{2} f[(w Q-B)(1+r)]} \\
& =-\frac{1}{\eta} \frac{[1-w(1+r)]-\bar{F}\left(Q^{*}\right)+w(1+r) \bar{F}[(w Q-B)(1+r)]}{-f\left(Q^{*}\right)+[w(1+r)]^{2} f[(w Q-B)(1+r)]} .
\end{aligned}
$$

From

$$
\begin{aligned}
\left(1-\frac{1}{\eta}\right)[1-w(1+r)]+\frac{1}{\eta} \bar{F}\left(Q^{*}\right) \\
=\frac{1}{\eta}[w(1+r)] \bar{F}\left[\left(w Q^{*}-B\right)(1+r)\right],
\end{aligned}
$$

we have

$$
\begin{aligned}
& (\eta-1)[1-w(1+r)] \\
& \quad=[w(1+r)] \bar{F}\left[\left(w Q^{*}-B\right)(1+r)\right]-\bar{F}\left(Q^{*}\right) .
\end{aligned}
$$

Inserting the above equation we have

$$
\begin{aligned}
& \frac{\partial Q^{*}}{\partial \eta} \\
& \quad=-\frac{1}{\eta-f\left(Q^{*}\right)+[w(1+r)]^{2} f[(w Q-B)(1+r)]} \\
& =-\frac{[1-w(1+r)]}{-f\left(Q^{*}\right)+[w(1+r)]^{2} f[(w Q-B)(1+r)]} \\
& >0
\end{aligned}
$$

Thus, $Q^{*}$ is increasing in $\eta$.

Corollary 3 shows that, under bank financing service and for any given wholesale price, the more risk-averse the retailer is, the more conservative the retailer will be in order quantity. This is because the more the retailer is concerned with risk, the less the retailer is conservative in ordering. It indicates that the risk-averse retailer is stimulated to avoid risk caused by stochastic demand by means of ordering less with bank financing service, which is same with the risk-neutral retailer. That is, under the conditions stated in Corollary 3, for any two newsvendors $i$ and $j$, if newsvendor $i$ is more riskaverse than newsvendor $j$, that is, $\eta_{i}<\eta_{j}$, then the optimal order quantity for newsvendor $i$ is not greater than that for newsvendor $j$ with bank financing service. Specifically, when the retailer is risk-neutral, that is, $\eta=1$ for any given $w$, the retailer's optimal order quantity $\bar{Q}^{*}$ will satisfy $\bar{F}\left(\bar{Q}^{*}\right)=$ $w(1+r) \bar{F}\left[\left(w \bar{Q}^{*}-B\right)(1+r)\right]$.

We have the following two conclusions for special cases. When the newsvendor is risk-neutral, that is, $\eta=1$, hence the optimal order quantity will be determined by $\bar{F}\left(\bar{Q}^{*}\right)=w(1+$ $r) \bar{F}\left[\left(w \bar{Q}^{*}-B\right)(1+r)\right]$, which is the maximum optimal order quantity of retailer with bank financing service. If $\eta \rightarrow 0$, the retailer is deeply risk-averse and the optimal order level satisfies $F\left(Q^{*}\right)=w(1+r) F\left[\left(w Q^{*}-B\right)(1+r)\right]$, which is the minimum optimal order quantity of retailer with bank financing service. Obviously, we have $Q^{*}<Q^{*}<\bar{Q}^{*}$. On the other hand, under the financing service of bank loan when the newsvendor is risk-averse the retailer has to repay his loan $w Q-B$ to the bank at the-end-of-the-sales season if he earns enough. Since the unsold units are neither salvage value nor return policy, the retailer will face the risk alone caused by stochastic market demand and the retailer would be conservative when ordering. So we have $\bar{Q}^{*} \leq Q^{C}$. From the perspective of the core supplier, the supplier as the leader would design a suitable wholesale price to restrict the retailer's order quantity, which could hurt the profits of the supplier and the entire supply chain. $\bar{Q}^{*} \leq Q^{C}$ also shows the coordinating function of the supplier to supply chain. Therefore, we have $\underline{Q}^{*}<Q^{*}<\bar{Q}^{*}<Q^{C}$.

Corollary 4. Under the criterion of $\eta-C V a R$, for risk-averse retailer,

(i) if it satisfies $0<\eta<\eta_{0}\left(\right.$ or $\left.0<\eta<\eta_{1}\right)$, then $\partial Q^{*} / \partial w>0\left(\right.$ or $\left.\partial Q^{*} / \partial r>0\right)$ and the optimal order quantity of the retailer is increasing in $w$ (or $r)$;

(ii) otherwise when $\eta_{0}<\eta \leq 1$ (or $\left.\eta_{1}<\eta \leq 1\right)$, we have $\partial Q^{*} / \partial w<0\left(\right.$ or $\left.\partial Q^{*} / \partial r<0\right)$ and the optimal order quantity of the retailer is decreasing in $w$ (or $r)$, where

$$
\begin{aligned}
\eta_{0}= & 1-\bar{F}[(w Q-B)(1+r)] \\
& \cdot\{1-w(1+r) Q h[(w Q-B)(1+r)]\},
\end{aligned}
$$




$$
\begin{aligned}
\eta_{1} & =1-\bar{F}[(w Q-B)(1+r)] \\
& \cdot\{1-(w Q-B)(1+r) h[(w Q-B)(1+r)]\} .
\end{aligned}
$$

Proof. For

$$
\begin{aligned}
& \frac{\partial Q^{*}}{\partial w} \\
& \quad=-\frac{\eta_{0}-\eta}{-f\left(Q^{*}\right)+[w(1+r)]^{2} f\left[\left(w Q^{*}-B\right)(1+r)\right]}, \\
& 0<w(1+r) Q^{*} h\left[\left(w Q^{*}-B\right)(1+r)\right] \\
& \bar{F}\left[\left(w Q^{*}-B\right)(1+r)\right]<1,
\end{aligned}
$$

it is easy to get $0<\eta_{0}<1$, where

$$
\begin{aligned}
\eta_{0}=1-\bar{F}\left[\left(w Q^{*}-B\right)(1+r)\right] \\
\cdot\left\{1-w(1+r) Q^{*} h\left[\left(w Q^{*}-B\right)(1+r)\right]\right\} .
\end{aligned}
$$

It is easy to know that the sign of $\partial Q^{*} / \partial w$ depends on the factor of $\eta$. It is similar to prove the monotonicity of $Q^{*}$ in $r$.

The results of Corollary 4 are interesting. The possible explanation may be as follows. In centralized supply chain, wholesale price has no effect on the optimal ordering and the expected profit of the supply chain. In decentralized case, if the retailer's risk-averse degree is low, that is, $\eta_{0}<\eta \leq 1$, the optimal order is decreasing in wholesale price $w$. In our model the retail price is fixed and exogenous, and increasing of retailer's order cost decreases the unit profit of newsvendor. Now higher demand needs to be realized so that the retailer's profit is guaranteed. Hence, the retailer has to reduce the optimal ordering to avoid exposure to surplus inventory. In case of $0<\eta<\eta_{0}$, the degree of retailer's risk aversion is high. Notice that, in Theorem 2 and Corollary 3, we have $\partial k(Q, v) / \partial Q=(\partial k(Q, v) / \partial \eta)(\partial \eta / \partial Q)>0$. Thus the expected profit of risk-averse retailer is increasing in regard to the ordering and the retailer is stimulated to order more quantity with the aim of offsetting the possible loss of profit.

Corollary 5. In decentralized case, under the criterion of $\eta-C V a R$, with the bank financing service the optimal order quantity $Q^{*}$ of risk-averse retailer is decreasing in $B$.

Proof. Let

$$
\begin{aligned}
G\left(Q^{*}, B\right)= & \left(1-\frac{1}{\eta}\right)[1-w(1+r)]+\frac{1}{\eta} \bar{F}\left(Q^{*}\right) \\
& -\frac{1}{\eta}[w(1+r)] \bar{F}\left[\left(w Q^{*}-B\right)(1+r)\right] .
\end{aligned}
$$

Applying the implicit function theorem and

$$
\begin{aligned}
1-w(1+r) & >0, \\
-f\left(Q^{*}\right)+[w(1+r)]^{2} f[(w Q-B)(1+r)] & <0
\end{aligned}
$$

yields

$$
\begin{aligned}
\frac{\partial Q^{*}}{\partial B} & =\frac{c(1+r)^{2} f\left[\left(w Q^{*}-B\right)(1+r)\right]}{-f\left(Q^{*}\right)+[w(1+r)]^{2} f\left[\left(w Q^{*}-B\right)(1+r)\right]} \\
& <0 .
\end{aligned}
$$

Thus, $Q^{*}$ is decreasing in $B$.

Intuitively, the more initial capital the retailer has, the more the retailer orders. However, this intuition does not hold in Corollary 5. According to the corollary, increase in $B$ loosens the boundary on the retailer's cash position. When the retailer has small initial fund, he orders more and inclines to accept bank financing service. When the retailer has large initial wealth, he will not be aggressive for the fear of going bankrupt. So the retailer will order less. To some extent, bank financing service can provoke the retailer to order more.

4.2. The Supplier's Model. The decision-making question of the risk-neutral supplier can be expressed as

$$
\max _{0<w<p} E \pi_{S}=\max _{0<w<p} E\left\{\min \left[\min \left\{\xi, Q^{*}\right\},\left(w Q^{*}-B\right)(1+r)\right]+B-c Q^{*}\right\}
$$

Following the retailer's decision, the supplier begins to decide the optimal wholesale price $w$. On one hand, since the risk-averse retailer does not have enough capital to order the optimal quantity, then $\left(w Q^{N}-B\right)(1+r) \geq 0$. On the other hand, we have $\left(w Q^{N}-B\right)(1+r) \leq Q^{N} \leq Q^{C}$. That is to say, $0 \leq\left(w Q^{N}-B\right)(1+r) \leq Q^{C}$ holds. The wholesale price $w \in[\underline{w}, \bar{w}]$ must satisfy $0 \leq\left(w Q^{N}-B\right)(1+r) \leq Q^{C}$. Then we have Theorem 6.

Theorem 6. In the decentralized case, the bank provides financing service for retailer with interest rater and $w \in[\underline{w}, \bar{w}]$. Then the optimal wholesale price satisfies the following: (i) If $\bar{w}<\widetilde{w}$, the optimal wholesale price is $\bar{w}$.

(ii) If $\underline{w}<\widetilde{w} \leq \bar{w}$, the optimal wholesale price is $\widetilde{w}$.

(iii) If $\widetilde{w} \leq \underline{w}$, the optimal wholesale price is $\underline{w}$.

Thus,

$$
\begin{aligned}
\eta_{0}=1-\bar{F}\left[\left(w Q^{*}-B\right)(1+r)\right] \\
\cdot\left\{1-w(1+r) Q^{*} h\left[\left(w Q^{*}-B\right)(1+r)\right]\right\}
\end{aligned}
$$

and $\widetilde{w}$ satisfies 


$$
\varepsilon(w)=\frac{\bar{F}\left(Q^{*}\right)\left[1-\left((1-\eta) / \bar{F}\left(Q^{*}\right)\right)-H\left(Q^{*}\right)\right]}{-(1-\eta) / \bar{F}\left[\left(w Q^{*}-B\right)(1+r)\right]+\left\{1-w(1+r) Q^{*} h\left[\left(w Q^{*}-B\right)(1+r)\right]\right\}}, \quad \varepsilon(w)=c .
$$

Proof. Since

$$
\begin{aligned}
& \frac{d \pi_{S}}{d w}=\frac{\partial \pi_{S}}{\partial w}+\frac{\partial \pi_{S}}{\partial Q^{*}} \frac{\partial Q^{*}}{\partial w} \\
& \quad=\frac{\partial Q^{*}}{\partial w}\left\{-\frac{\bar{F}\left[\left(w Q^{*}-B\right)(1+r)\right]\left[-Q^{*} f\left(Q^{*}\right)-w(1+r)(1-\eta)+w(1+r) \bar{F}\left[\left(w Q^{*}-B\right)(1+r)\right]\right]}{(1-\eta)-\bar{F}\left[\left(w Q^{*}-B\right)(1+r)\right]\left[1-w(1+r) Q^{*} h\left(w Q^{*}-B\right)(1+r)\right]}-c\right\}, \\
& {[w(1+r)] \bar{F}\left[\left(w Q^{*}-B\right)(1+r)\right]=-(1-\eta)[1-w(1+r)]+\bar{F}\left(Q^{*}\right),}
\end{aligned}
$$

it follows

$$
\frac{d \pi_{S}}{d w}=\frac{\partial Q^{*}}{\partial w}\left\{\frac{\bar{F}\left(Q^{*}\right)\left\{1-(1-\eta) / \bar{F}\left(Q^{*}\right)-H\left(Q^{*}\right)\right\}}{-(1-\eta) / \bar{F}\left[\left(w Q^{*}-B\right)(1+r)\right]+\left[1-w(1+r) Q^{*} h\left(w Q^{*}-B\right)(1+r)\right]}-c\right\}=\frac{\partial Q^{*}}{\partial w}[\varepsilon(w)-c] .
$$

In case of $\eta_{0}<\eta \leq 1, \partial Q^{*} / \partial w<0$.

Consequently, we have

$$
\begin{aligned}
& \frac{-(1-\eta)}{\overline{\bar{F}}\left[\left(w Q^{*}-B\right)(1+r)\right]} \\
& \quad+\left[1-w(1+r) Q^{*} h\left(w Q^{*}-B\right)(1+r)\right]>0 .
\end{aligned}
$$

The sign of $d \pi_{S} / d w$ depends on $\varepsilon(w)-c$.

If $w_{0}$ satisfies $1-(1-\eta) / \bar{F}\left(Q^{*}\right)-H\left(Q^{*}\right)=0$, then $H\left(Q^{*}\right)$ and $(1-\eta) / \bar{F}\left(Q^{*}\right)$ are decreasing in wholesale price $w$. Therefore, if $w<w_{0}$, then $1-(1-\eta) / \bar{F}\left(Q^{*}\right)-H\left(Q^{*}\right)>0$ and $\varepsilon(w)-c<0$, which mean $d \pi_{S} / d w>0$.

If $w>w_{0}$, we have $1-(1-\eta) / \bar{F}\left(Q^{*}\right)-H\left(Q^{*}\right)>0$ and $\varepsilon(w)>0$. If we can prove that $\varepsilon(w)$ is increasing in $w$, then $d \pi_{S} / d w<0$ is obtained and $\pi_{S}$ is unimodal (to prove $d \varepsilon(w) / d w>0)$.

$$
\begin{gathered}
\frac{d \varepsilon(w)}{d w}=\left(\left[-\frac{(1-\eta) f\left(Q^{*}\right)}{\bar{F}^{2}\left(Q^{*}\right)}-H^{\prime}\left(Q^{*}\right)\right]\left(Q^{*}\right)^{\prime}[1\right. \\
-\frac{1-\eta}{\bar{F}\left(w Q^{*}-B\right)(1+r)}-w(1+r) Q^{*} h\left(w Q^{*}-B\right) \\
\cdot(1+r)]+\left[1-\frac{1-\eta}{\bar{F}\left(Q^{*}\right)}-H\left(Q^{*}\right)\right] \\
\cdot\left[\frac{(1-\eta) f\left(w Q^{*}-B\right)(1+r)}{\bar{F}^{2}\left(w Q^{*}-B\right)(1+r)}+h\left(w Q^{*}-B\right)(1\right.
\end{gathered}
$$

$$
\begin{aligned}
& \left.+r)+w(1+r) Q^{*} h^{\prime}\left(w Q^{*}-B\right)(1+r)\right]_{w}^{\prime}(w(1 \\
& \left.\left.+r) Q^{*}\right)^{\prime}\right)\left(\left[1-\frac{1-\eta}{\bar{F}\left(w Q^{*}-B\right)(1+r)}-w(1+r)\right.\right.
\end{aligned}
$$$$
\left.\left.\cdot Q^{*} h\left(w Q^{*}-B\right)(1+r)\right]^{2}\right)^{-1}>\left(\left[1-\frac{1-\eta}{\bar{F}\left(Q^{*}\right)}\right.\right.
$$$$
\left.-H\left(Q^{*}\right)\right]\left(Q^{*}\right)^{\prime}\left[\frac{(1-\eta) f\left(w Q^{*}-B\right)(1+r)}{\bar{F}^{2}\left(w Q^{*}-B\right)(1+r)}\right.
$$$$
+h\left(w Q^{*}-B\right)(1+r)+w(1+r) Q^{*} h^{\prime}\left(w Q^{*}-B\right)
$$$$
\cdot(1+r)-\frac{(1-\eta) f\left(Q^{*}\right)}{\bar{F}^{2}\left(Q^{*}\right)}-h\left(Q^{*}\right)
$$$$
\left.\left.-Q^{*} h^{\prime}\left(Q^{*}\right)\right]\right)\left(\left[1-\frac{1-\eta}{\bar{F}\left(w Q^{*}-B\right)(1+r)}\right.\right.
$$$$
\left.\left.-w(1+r) Q^{*} h\left(w Q^{*}-B\right)(1+r)\right]^{2}\right)^{-1}=([1
$$$$
\left.-\frac{1-\eta}{\bar{F}\left(Q^{*}\right)}-H\left(Q^{*}\right)\right]\left(Q^{*}\right)^{\prime}\left\{-\left[\frac{(1-\eta) f\left(Q^{*}\right)}{\bar{F}^{2}\left(Q^{*}\right)}\right.\right.
$$ 


$$
\begin{aligned}
& \left.-\frac{(1-\eta) f\left(w Q^{*}-B\right)(1+r)}{\bar{F}^{2}\left(w Q^{*}-B\right)(1+r)}\right]-\left[h\left(Q^{*}\right)\right. \\
& \left.-h\left(w Q^{*}-B\right)(1+r)\right]-\left[Q^{*} h^{\prime}\left(Q^{*}\right)\right. \\
& \left.\left.\left.-w(1+r) Q^{*} h^{\prime}\left(w Q^{*}-B\right)(1+r)\right]\right\}\right)([1 \\
& -\frac{1-\eta}{\bar{F}\left(w Q^{*}-B\right)(1+r)}-w(1+r) Q^{*} h\left(w Q^{*}-B\right) \\
& \left.\cdot(1+r)]^{2}\right)^{-1}>0 .
\end{aligned}
$$

Since $(1-\eta) f\left(w Q^{*}-B\right)(1+r) / \bar{F}^{2}\left(w Q^{*}-B\right)(1+r)>0$, $(1-\eta) f\left(Q^{*}\right) / \bar{F}^{2}\left(Q^{*}\right)-h\left(Q^{*}\right)-h\left(w Q^{*}-B\right)(1+r)>0$ and $Q^{*} h^{\prime}\left(Q^{*}\right)-w(1+r) Q^{*} h^{\prime}\left(w Q^{*}-B\right)(1+r)>0$. $)$

When $w>w_{0}, \varepsilon(w)$ is increasing in $w$. Let $\widetilde{w}$ satisfy $\varepsilon(w)-$ $c=0$. When $w<\widetilde{w}$, we have $d \pi_{S} / d w>0$. When $w=\widetilde{w}$, we have $d \pi_{S} / d w=0$. When $w>\widetilde{w}$, we have $d \pi_{S} / d w<0$. Combining these outcomes with $w \in[\underline{w}, \bar{w}]$, Theorem 6 is obtained.

According to Theorem 2, if $0<\eta<\eta_{0}$, we have $\partial Q^{*} / \partial w>$ 0 and

$$
\begin{aligned}
& {\left[w(1+r) Q^{*}\right]^{\prime}=(1+r)\left(Q^{*}+w \frac{\partial Q^{*}}{\partial w}\right)} \\
& =-(1+r) \\
& \quad \cdot \frac{(1-\eta)-\bar{F}\left(Q^{*}\right)\left[1-H\left(Q^{*}\right)\right]}{-f\left(Q^{*}\right)+[w(1+r)]^{2} f\left[\left(w Q^{*}-B\right)(1+r)\right]}
\end{aligned}
$$

$>0$.

That is to say, when

$$
\begin{aligned}
1- & \eta>\bar{F}\left[\left(w Q^{*}-B\right)(1+r)\right] \\
\cdot & {\left[1-w(1+r) Q^{*} h\left(w Q^{*}-B\right)(1+r)\right]>\bar{F}\left(Q^{*}\right) } \\
\cdot & {\left[1-H\left(Q^{*}\right)\right], }
\end{aligned}
$$

we have

$$
\begin{aligned}
1- & \frac{1-\eta}{\bar{F}\left(Q^{*}\right)}-H\left(Q^{*}\right) \\
< & \frac{-(1-\eta)}{\bar{F}\left[\left(w Q^{*}-B\right)(1+r)\right]} \\
& +\left[1-w(1+r) Q^{*} h\left(w Q^{*}-B\right)(1+r)\right]<0,
\end{aligned}
$$

$\varepsilon(w)>1$.

Combining $\bar{F}\left(Q^{*}\right)>\bar{F}\left(\bar{Q}^{*}\right)>\bar{F}\left(Q^{C}\right)=c$, which means that $\bar{F}\left(Q^{*}\right)>c$ and $\varepsilon(w)-c>0$, thus we have $d \pi_{S} / d w=$ $\left(\partial Q^{*} / \partial w\right)[\varepsilon(w)-c]>0$. This completes proof.
Theorem 6 shows that optimal wholesale price of supplier is divided into three cases according to $\underline{w}$ and $\bar{w}$. The theorem gives the sufficient conditions for the uniqueness of the wholesale price, which is related to the retailer's initial capital and bank interest rate.

\section{Numerical Examples}

In order to illustrate the ideas previously exposed, we proceed with several numerical examples using the distribution functions for the random variable $\xi \sim N\left(500,200^{2}\right)$. We adopt the parameters as follows: $w=0.8, B=50, \eta=0.5, r=$ 0.05 . The reasons for the value choice of the parameters are as follows. We assume the distribution functions of random variable, $\xi \sim N\left(500,200^{2}\right)$, which satisfies the property of failure rate and generalized failure rate. But it is important to note that our following observations are robust in other distribution functions, such as exponential distribution and uniform distribution, as long as they satisfy the property of $\xi$. We set $w=0.8$ and $c=0.1$, which satisfy the assumptions of $1=p>w(1+r)>c$. The above assumption would guarantee the agents in supply chain have the incentives to participate in the businesses in supply chain's operations. In order to be consistent with hypothesis of $0<\eta<1, w Q>B$, and the real business, we set $\eta=0.5, B=50$, and $r=0.05$.

We alter one of the above variables and keep the other two variables unchanged. For example, we let wholesale price, the initial budget, and interest rate fixed, changing risk aversion coefficient to investigate how it affects the newsvendor's ordering decisions, which is shown in Figure 1(a). In Figures 1(b), 1(c), and 1(d) we alter initial budget, wholesale price, and interest rate, respectively, with the other three variables remaining unchanged. The optimal order quantity is strictly decreasing in the initial budget, wholesale price, and interest rate, and the more risk-averse the newsvendor is, the less the newsvendor orders, as illustrated in Figure 1.

Similar to the set of the first numerical example, the stochastic demand obeys the normcdf distribution $\xi \sim$ $N\left(500,200^{2}\right)$ and the parameters as follows. $w=0.8, B=$ $50, \eta=0.5, r=0.05$. We also take the same approach to analyze the profit of the member in supply chain with the CVaR criterion. The impacts of the four parameters on the profit of member in supply chain are demonstrated in Figure 2, respectively.

In the third set of the numerical results, we make analysis of $\eta_{0}$ and $\eta_{1}$ on the retailer's profit. The parameters are set as follows. $w=0.8, B=50, \eta=0.5, r=0.05$, and $c=0.1$. The stochastic demand obeys the normcdf distribution. It reflects that the retailer profit in consideration of the risk aversion under CVaR criterion is a unimodal function of $\eta_{0}$ and $\eta_{1}$, respectively, as depicted in Figure 3. This implies that the retailer's CVaR profit is not always monotonic in $\eta_{0}$ and $\eta_{1}$, which is different to the risk-averse factor $\eta$ of retailer.

Figure 4 illustrates relationship between the order quantity and the retailer's profit with the different value of $\eta$ and $r$. Figure 4 indicates that the retailer's profit and optimal order quantity are the biggest when the retailer is risk-neutral and interest rate equals zero. When the retailer is risk-averse 


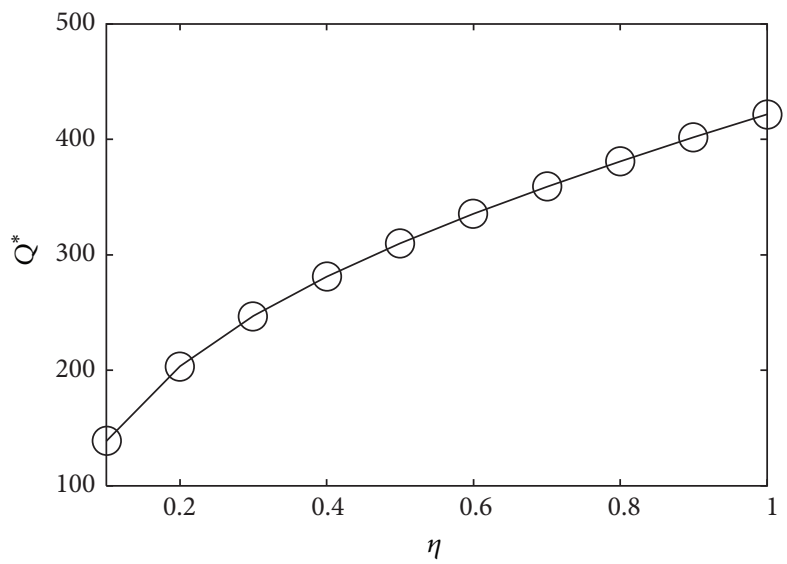

(a)

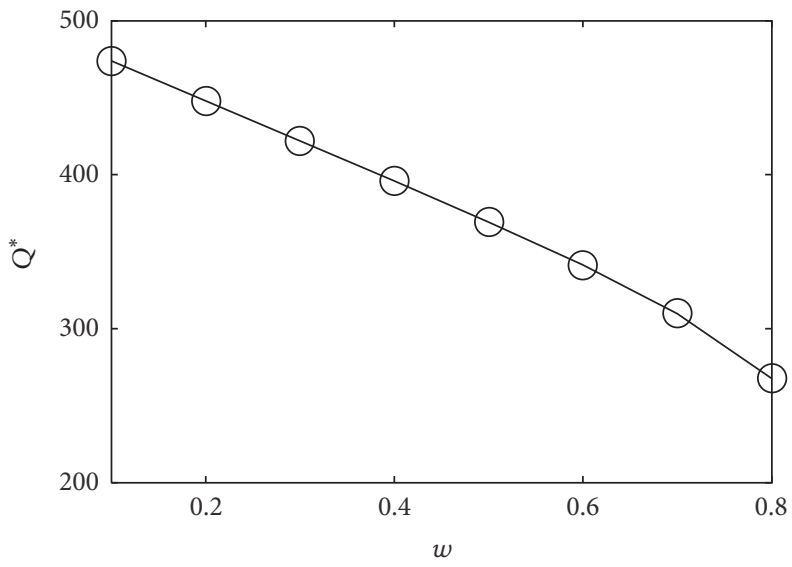

(c)

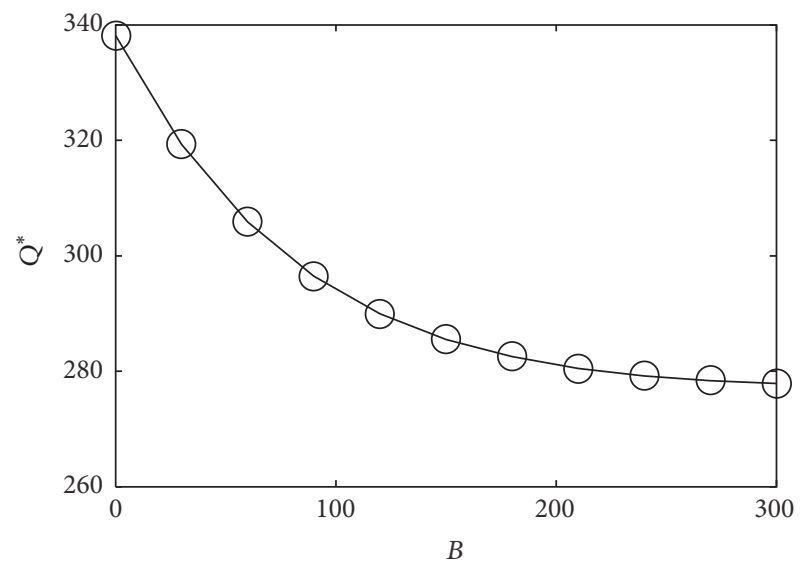

(b)

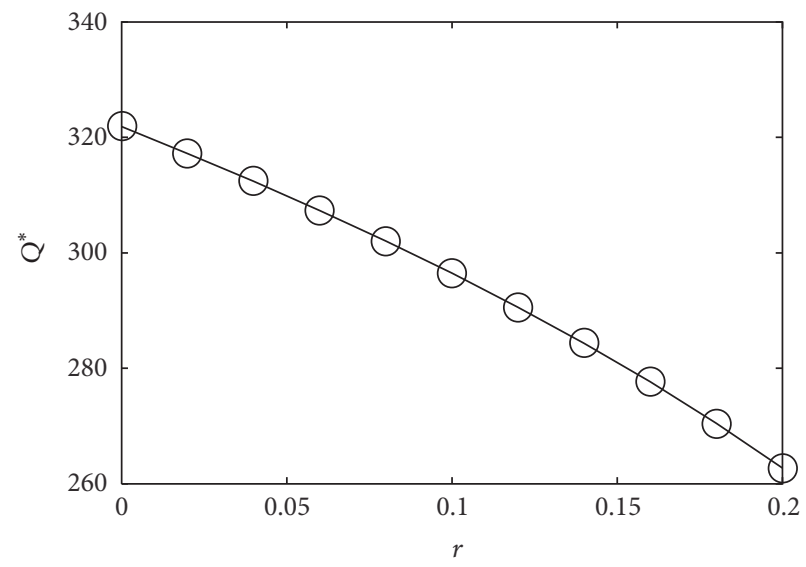

(d)

FIGURE 1: Impact of $\eta, B, w$, and $r$ on retailer's order quantity.

and budget-constrained the optimal ordering and profit will decrease.

Figure 5 shows how the optimal order quantity, retailer's profit, and supply chain profit vary as the initial budget $B$, where the distribution functions for the random variable $\xi \sim$ $N\left(500,200^{2}\right), w=0.8, \eta=0.2, r=0.05, c=0.4$. The centralized optimal ordering and profit of supply chain are 916.2907 and 132.5231. Let $Q^{N}, \pi_{r}^{N}$, and $\pi^{N}$ be retailer's optimal ordering, profit, and the supply chain profit when retailer is budgetsufficient. $Q^{*}, \pi_{r}$, and $\pi$ are retailer's optimal ordering, profit, and the supply chain profit with budget-constrained under bank financing service. When retailer is budget-constrained and there is no finance service, $Q_{0}, \pi_{r}^{0}$, and $\pi^{0}$ are the optimal ordering, profit, and the supply chain profit. It is worth noting that under bank financing service the optimal order quantity and profit depend on the financing size of the financing service of bank loan. The results tell us that the less the retailer has initial budget, the higher profit of retailer and supply chain. At this point, the financing service of bank loan can improve the performance of the supply chain to some extent.

\section{Conclusion}

In the paper, by using $\eta$-CVaR criterion as a reference we consider the budget-constrained newsvendor model in which a risk-averse newsvendor sells products with a stochastic demand and places an order quantity from a risk-neutral supplier who decides on the wholesale price. We offer a description of the risk-averse newsvendor's ordering model and the supplier's wholesale pricing model and analyze how the financing service of bank loan impacts the risk-averse newsvendor's decision and how the risk-averse behavior of the retailer influences the optimal ordering and pricing in supply chain. We also examine existence and uniqueness of optimal strategies to the problem in retailer's expected risk model and supplier's profit model. Then we make the sensitivity analysis of important parameters such as riskaverse factor, initial budget, wholesale price, and interest rate and illustrate numerical examples to conduct theoretical results. We find that the risk-averse retailer's optimal order quantity increases in risk aversion factor. The optimal order quantity is decreasing in initial budget, wholesale price, and interest rate. It is worth nothing that this study has highlighted how the risk-averse factor and the financing service of bank loan may affect the operation and performance in supply chain using the CVaR criterion.

This paper considers a simple dyadic supply chain. It seems interesting to extend our study to examine the influences of risk aversion and budget constraints in the existence 

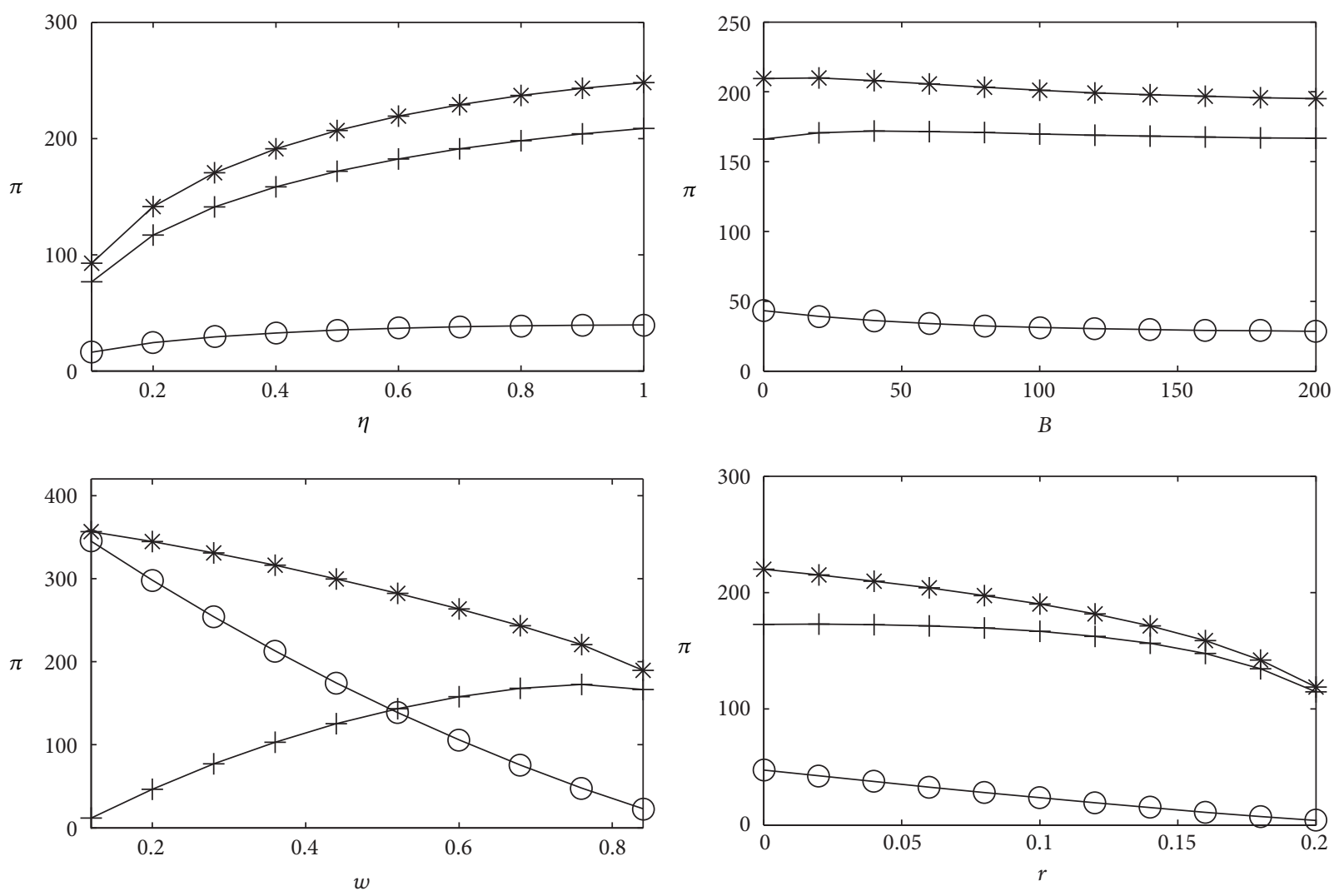

$\bigcirc \pi_{r} \quad$ * $\pi_{r}+\pi_{s}$

$\uparrow \pi_{s}$

$\bigcirc \pi_{r}$
$+\pi_{s}$

米 $\pi_{r}+\pi_{s}$

FIGURE 2: Impact of $\eta, B, w$, and $r$ on the profit of member in supply chain.

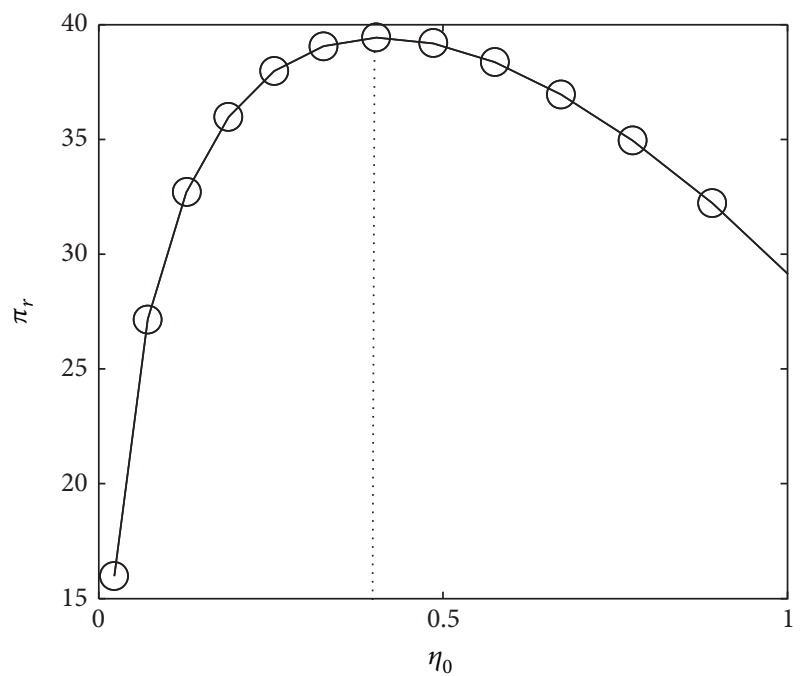

(a)

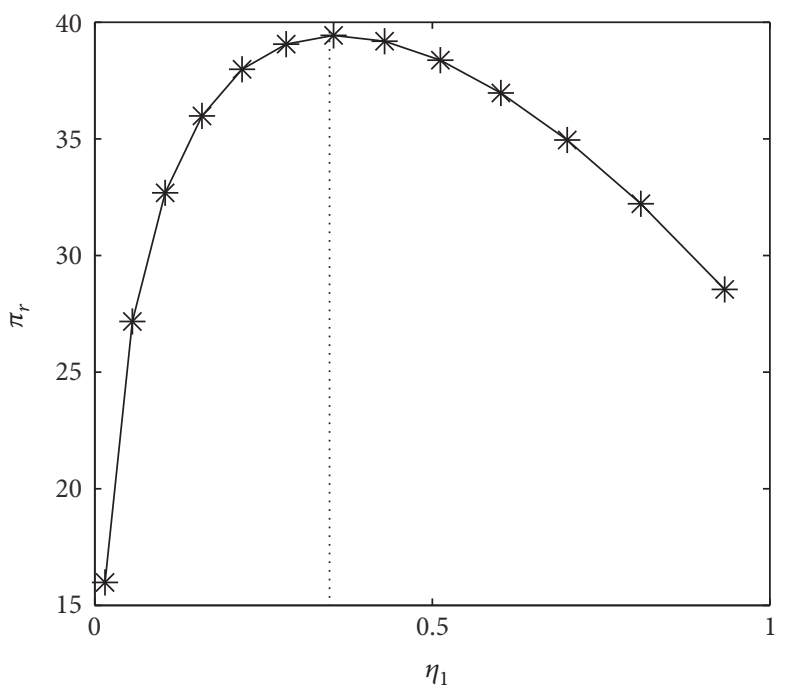

(b)

FIgURE 3: Impact of $\eta_{0}$ and $\eta_{1}$ on retailer's profit $\pi_{r}$.

of competition among multiple supplier or multiple retailers. For simplification, we only consider the risk aversion and budget constraints of retailer. In fact the operation problems of supply chain are also affected by the risk preference and budget constraints of supplier. Furthermore, further work also includes investigation of the effect of using other performance measures such as prospect theory, fairness concerns, and mean CVaR on supply chain management. 


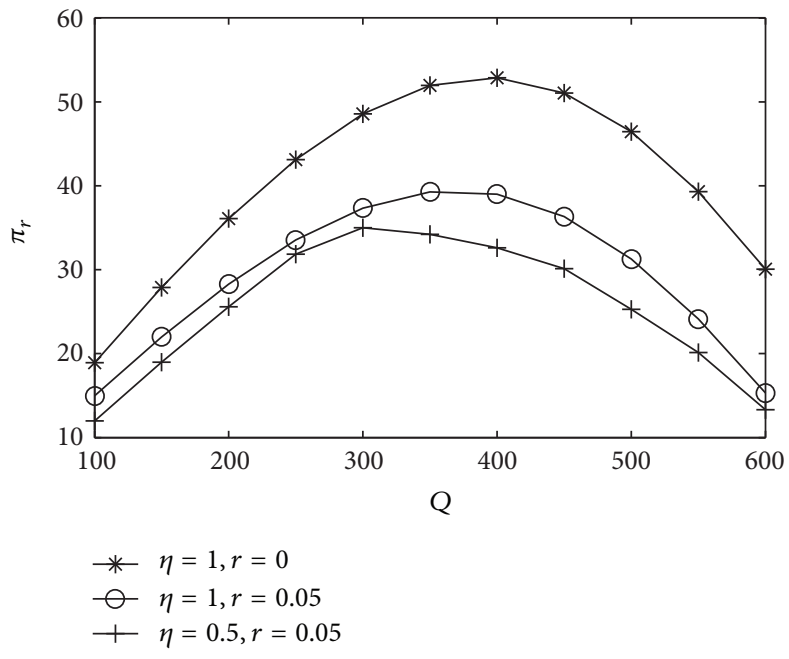

FIGURE 4: Impact of $\eta$ and $r$ on retailer's profit.

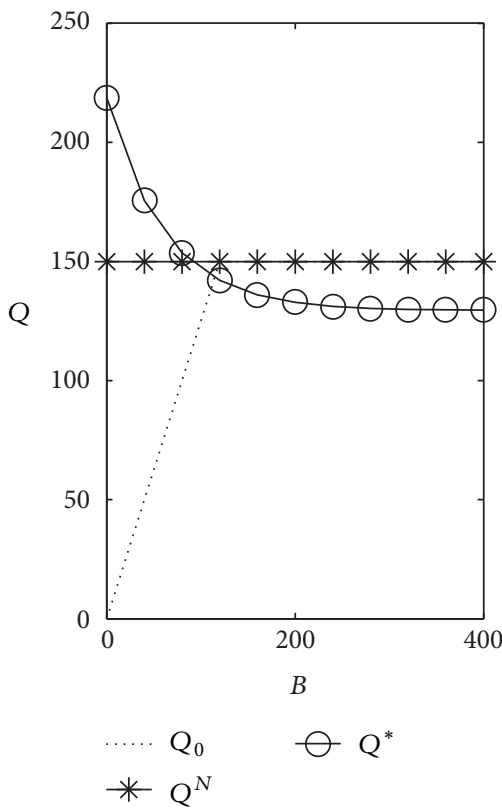

(a)

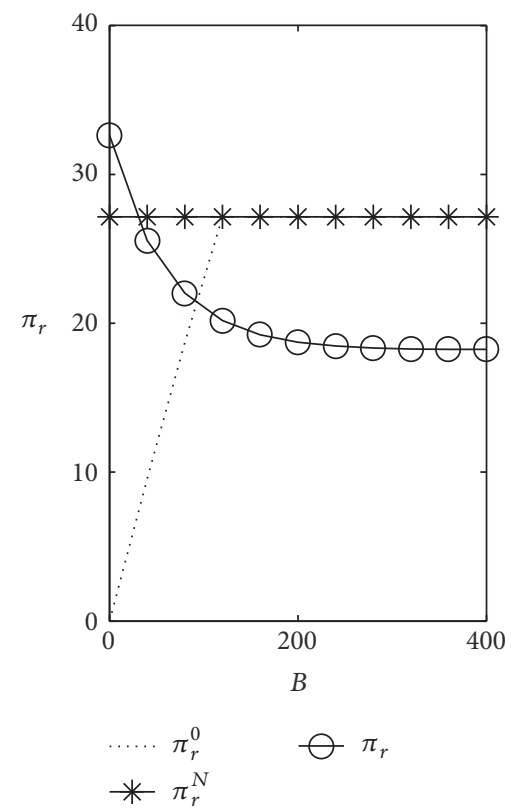

(b)

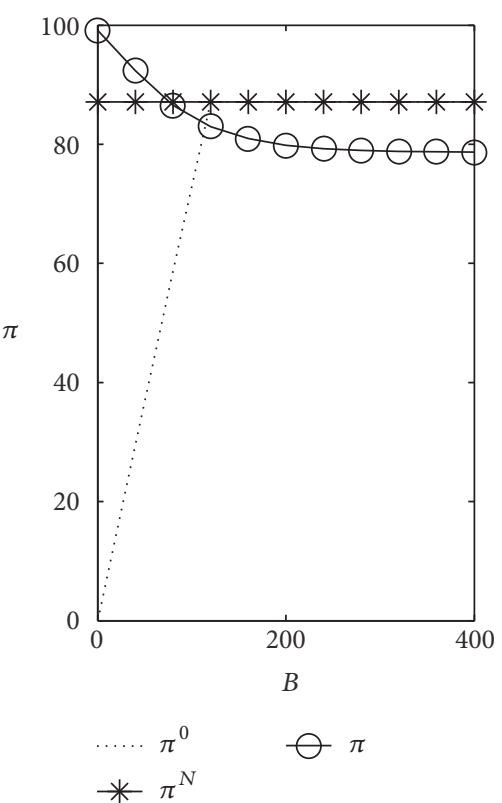

(c)

FIgURE 5: Impact of initial budget $B$ on ordering and profit.

More complicated models may provide useful managerial insights in future research.

\section{Competing Interests}

The author declares that they have no competing interests.

\section{Acknowledgments}

This work was financially supported by Ministry of Education, Humanities and Social Science Project (16YJC630004, 14YJAZH095), the Key Project of the National Natural Science Foundation of China (71131003), and Project of the
National Natural Science Foundation of China (71371075, 71520107001, and 71501077).

\section{References}

[1] M. Ayyagari, T. Beck, and A. Demirguc-Kunt, "Small and medium enterprises across the globe," Small Business Economics, vol. 29, no. 4, pp. 415-434, 2007.

[2] Y. Bai and J. Zhang, "Financial integration and international risk sharing," Journal of International Economics, vol. 86, no. 1, pp. 17-32, 2012.

[3] W. Barnett, "What's in a name? A brief overview of asset-based lending," Secured Lender, vol. 53, pp. 80-81, 1997. 
[4] L. Ma, W. Xue, Y. Zhao, and X. Lin, "Loss-averse inventory and borrowing decisions with constraints on working capital in fashion and textiles industry," Mathematical Problems in Engineering, vol. 2013, Article ID 657641, 9 pages, 2013.

[5] B. Zhang, D. Wu, L. Liang, and D. L. Olson, "Supply chain loss averse newsboy model with capital constraint," IEEE Transactions on Systems, Man, and Cybernetics: Systems, vol. 46, no. 5, pp. 646-658, 2016.

[6] X.-F. Chen, "The integrated logistics and financing service in supply chain with capital constraints," in Proceedings of the IEEE International Conference on Service Operations and Logistics, and Informatics (IEEE/SOLI '08), pp. 2837-2842, IEEE, Beijing, China, October 2008.

[7] X. Chen and G. Cai, "Joint logistics and financial services by a 3PL firm," European Journal of Operational Research, vol. 214, no. 3, pp. 579-587, 2011.

[8] L. J. Neumann and O. Morgenstern, Theory of Games and Economic Behavior, Princeton University Press, Princeton, NJ, USA, 1947.

[9] P. Jorion, Financial Risk Manager Handbook 2001-2002, John Wiley \& Sons, 2001.

[10] G. P. Szegö, Ed., Risk Measures for the 21st Century, vol. 1, John Wiley \& Sons, New York, NY, USA, 2004.

[11] Y. Wei and T.-M. Choi, "Mean-variance analysis of supply chains under wholesale pricing and profit sharing schemes," European Journal of Operational Research, vol. 204, no. 2, pp. 255-262, 2010.

[12] T.-M. Choi and C.-H. Chiu, "Mean-downside-risk and meanvariance newsvendor models: implications for sustainable fashion retailing," International Journal of Production Economics, vol. 135, no. 2, pp. 552-560, 2012.

[13] T.-M. Choi and C.-H. Chiu, Risk Analysis in Stochastic Supply Chains, vol. 178, Springer, New York, NY, USA, 2012.

[14] K. Jörnsten, S. L. Nonås, L. Sandal, and J. Ubøe, "Transfer of risk in the newsvendor model with discrete demand," Omega, vol. 40, no. 3, pp. 404-414, 2012.

[15] Y. Chen, M. Xu, and G. Zhang, "A risk-averse newsvendor model under the decision criterion," Operation Research, vol. 57, no. 4, pp. 1040-1044, 2009.

[16] L. Yang, M. Xu, G. Yu, and H. Zhang, "Supply chain coordination with CVaR criterion," Asia-Pacific Journal of Operational Research, vol. 26, no. 1, pp. 135-160, 2009.

[17] R. T. Rockafellar and S. Uryasev, "Optimization of conditional value-at-risk," Journal of Risk, vol. 2, pp. 21-42, 2000.

[18] R. T. Rockafellar and S. Uryasev, "Conditional value-at-risk for general loss distributions," Journal of Banking and Finance, vol. 26, no. 7, pp. 1443-1471, 2002.

[19] B. Tomlin and Y. Wang, "On the value of mix flexibility and dual sourcing in unreliable newsvendor networks," Manufacturing \& Service Operations Management, vol. 7, no. 1, pp. 37-57, 2005.

[20] J.-Y. Gotoh and Y. Takano, "Newsvendor solutions via conditional value-at-risk minimization," European Journal of Operational Research, vol. 179, no. 1, pp. 80-96, 2007.

[21] S. Choi and A. Ruszczyński, "A risk-averse newsvendor with law invariant coherent measures of risk," Operations Research Letters, vol. 36, no. 1, pp. 77-82, 2008.

[22] L. Ma, F. Liu, S. Li, and H. Yan, "Channel bargaining with riskaverse retailer," International Journal of Production Economics, vol. 139, no. 1, pp. 155-167, 2012.

[23] M. Wu, S. X. Zhu, and R. H. Teunter, "A risk-averse competitive newsvendor problem under the CVaR criterion," International Journal of Production Economics, vol. 156, pp. 13-23, 2014.
[24] J. Dai and W. Meng, "A risk-averse newsvendor model under marketing-dependency and price-dependency," International Journal of Production Economics, vol. 160, pp. 220-229, 2015.

[25] F. Modigliani and M. H. Miller, "The cost of capital, Corporation Finance and the Theory of Investment," The American Economic Review, vol. 48, no. 3, pp. 261-297, 1958.

[26] M. Harris and A. Raviv, "The theory of capital structure," The Journal of Finance, vol. 46, no. 1, pp. 297-355, 1991.

[27] V. Babich and M. J. Sobel, "Pre-IPO operational and financial decisions," Management Science, vol. 50, no. 7, pp. 935-948, 2004.

[28] J. A. Buzacott and R. Q. Zhang, "Inventory management with asset-based financing," Management Science, vol. 50, no. 9, pp. 1274-1292, 2004.

[29] M. A. Petersen and R. G. Rajan, "Trade credit: theories and evidence," Review of Financial Studies, vol. 10, no. 3, pp. 661-691, 1997.

[30] Y.-W. Zhou, Y.-G. Zhong, and M. I. Wahab, "How to make the replenishment and payment strategy under flexible two-part trade credit," Computers \& Operations Research, vol. 40, no. 5, pp. 1328-1338, 2013.

[31] S. K. Goyal, "Economic order quantity under conditions of permissible delay in payments," Journal of the Operational Research Society, vol. 36, no. 4, pp. 335-338, 1985.

[32] S. K. Goyal, ““'A joint economic-lot-size model for purchaser and vendor": a comment," Decision Sciences, vol. 19, no. 1, pp. 236-241, 1988.

[33] J.-T. Teng, "On the economic order quantity under conditions of permissible delay in payments," Journal of the Operational Research Society, vol. 53, no. 8, pp. 915-918, 2002.

[34] H.-C. Chang, C.-H. Ho, L.-Y. Ouyang, and C.-H. Su, “The optimal pricing and ordering policy for an integrated inventory model when trade credit linked to order quantity," Applied Mathematical Modelling. Simulation and Computation for Engineering and Environmental Systems, vol. 33, no. 7, pp. 2978-2991, 2009.

[35] A. A. Taleizadeh, D. W. Pentico, M. Saeed Jabalameli, and M. Aryanezhad, "An EOQ model with partial delayed payment and partial backordering," Omega (United Kingdom), vol. 41, no. 2, pp. 354-368, 2013.

[36] Q. Zhang, Y.-C. Tsao, and T.-H. Chen, "Economic order quantity under advance payment," Applied Mathematical Modelling, vol. 38, no. 24, pp. 5910-5921, 2014.

[37] Y. Wang, X. Sun, and F. Meng, "On the conditional and partial trade credit policy with capital constraints: a Stackelberg model," Applied Mathematical Modelling, vol. 40, no. 1, pp. 1-18, 2016.

[38] S. Yang and J. Birge, "How inventory is (should be) financed: trade credit in supply chains with demand uncertainty and costs of financial distress," Working Paper, London Business School, London, UK, 2010.

[39] X. Chen and A. Wang, "Trade credit contract with limited liability in the supply chain with budget constraints," Annals of Operations Research, vol. 196, pp. 153-165, 2012.

[40] Y.-W. Zhou, Z.-L. Wen, and X. Wu, "A single-period inventory and payment model with partial trade credit," Computers \& Industrial Engineering, vol. 90, pp. 132-145, 2015.

[41] J. Zhou and H. Groenevelt, "Impacts of financial collaboration in a three-party supply chain," Working Paper, University of Rochester, Rochester, NY, USA, 2007. 
[42] N. N. Yan and B. W. Sun, "Coordinating loan strategies for supply chain financing with limited credit," OR Spectrum, vol. 35, no. 4, pp. 1039-1058, 2013.

[43] M. Dada and Q. Hu, "Financing newsvendor inventory," Operations Research Letters, vol. 36, no. 5, pp. 569-573, 2008.

[44] C. H. Lee and B.-D. Rhee, "Coordination contracts in the presence of positive inventory financing costs," International Journal of Production Economics, vol. 124, no. 2, pp. 331-339, 2010.

[45] P. Kouvelis and W. Zhao, "The newsvendor problem and priceonly contract when bankruptcy costs exist," Production and Operations Management, vol. 20, no. 6, pp. 921-936, 2011.

[46] X. Feng, I. Moon, and K. Ryu, "Supply chain coordination under budget constraints," Computers and Industrial Engineering, vol. 88, pp. 487-500, 2015.

[47] X. Gan, S. P. Sethi, and H. Yan, "Channel coordination with a risk-neutral supplier and a downside-risk-averse retailer," Production \& Operations Management, vol. 14, no. 1, pp. 80-89, 2005.

[48] C.-C. Hsieh and Y.-T. Lu, "Manufacturer's return policy in a two-stage supply chain with two risk-averse retailers and random demand," European Journal of Operational Research, vol. 207, no. 1, pp. 514-523, 2010.

[49] M. Xu, Q. Wang, and L. Ouyang, "Coordinating contracts for two-stage fashion supply chain with risk-averse retailer and price-dependent demand," Mathematical Problems in Engineering, vol. 2013, Article ID 259164, 12 pages, 2013.

[50] B. Li, P. Chen, Q. Li, and W. Wang, "Dual-channel supply chain pricing decisions with a risk-averse retailer," International Journal of Production Research, vol. 52, no. 23, pp. 7132-7147, 2014.

[51] B. Li, P.-W. Hou, P. Chen, and Q.-H. Li, "Pricing strategy and coordination in a dual channel supply chain with a risk-averse retailer," International Journal of Production Economics, vol. 178, pp. 154-168, 2016.

[52] G. P. Cachon, "Supply chain coordination with contracts," Handbooks in Operations Research and Management Science, vol. 11, pp. 227-339, 2003.

[53] M. A. Lariviere and E. L. Porteus, "Selling to the newsvendor: an analysis of price-only contracts," Manufacturing \& Service Operations Management, vol. 3, no. 4, pp. 293-305, 2001. 


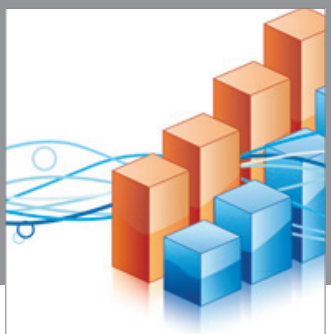

Advances in

Operations Research

vatem alat4

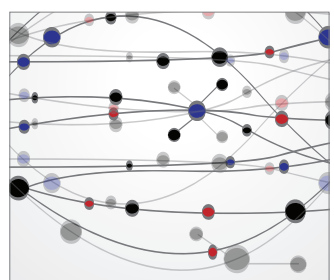

\section{The Scientific} World Journal
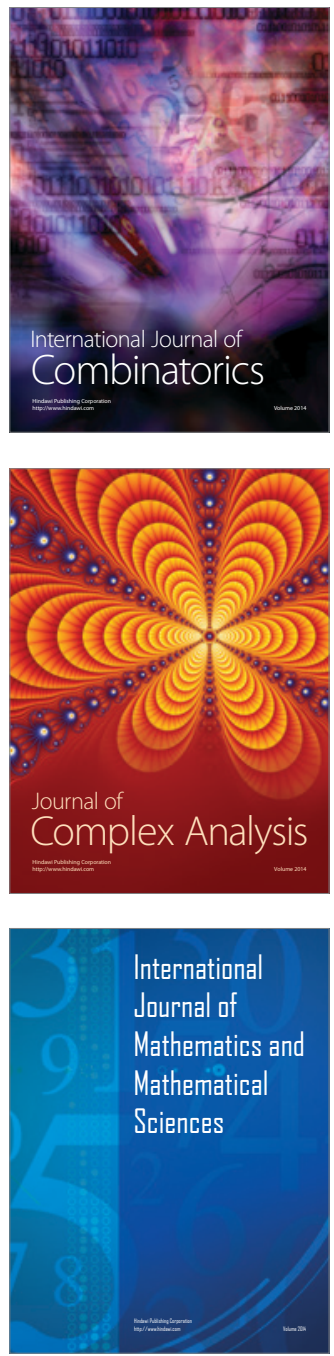
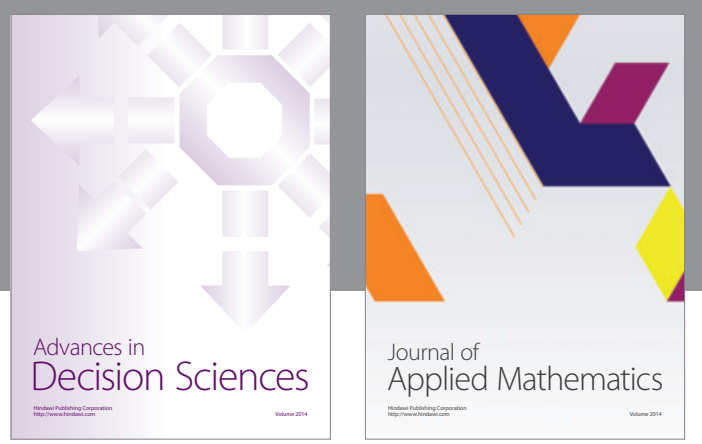

Algebra

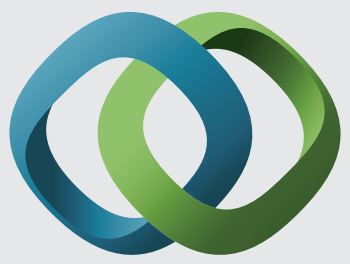

\section{Hindawi}

Submit your manuscripts at

https://www.hindawi.com
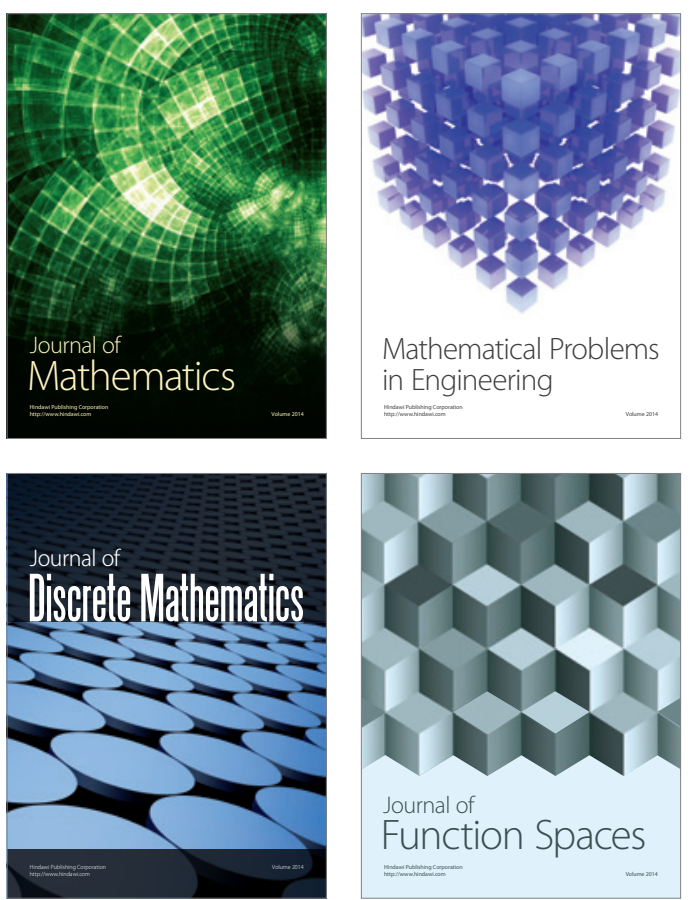

Mathematical Problems in Engineering
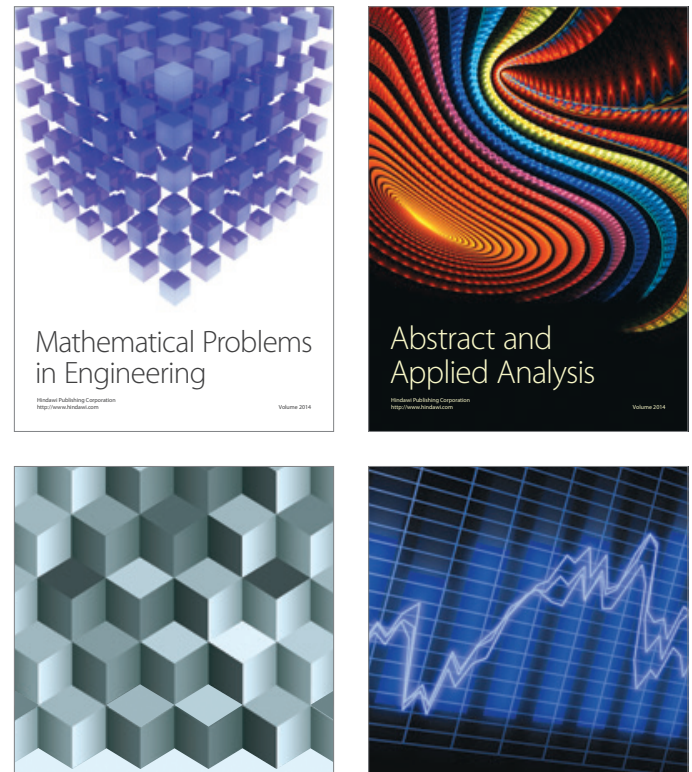

Journal of

Function Spaces

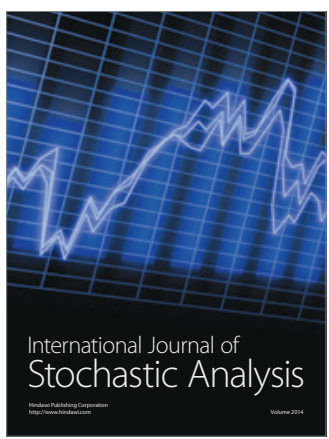

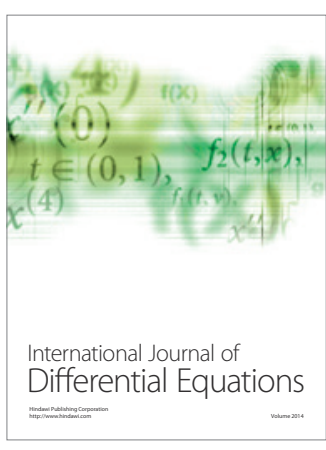
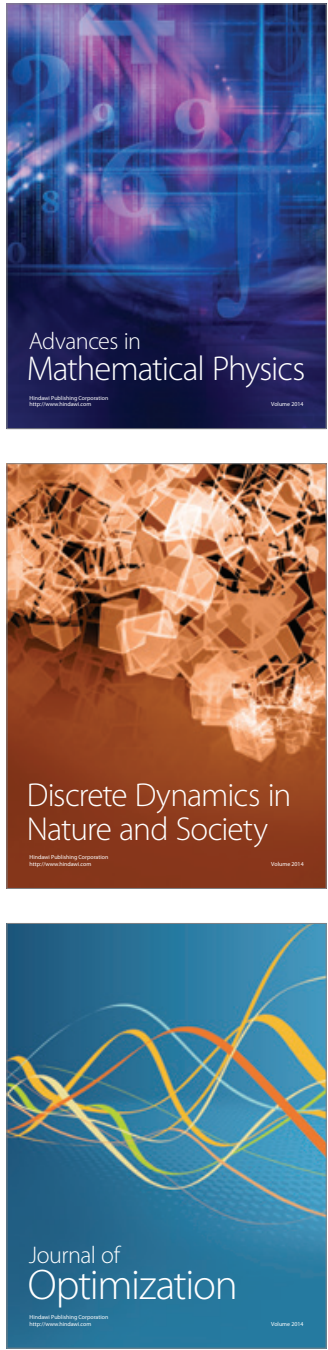